\title{
New iteration scheme for numerical reckoning fixed points of nonexpansive mappings
}

\author{
Dipti Thakur ${ }^{1}$, Balwant Singh Thakur ${ }^{1}$ and Mihai Postolache ${ }^{2^{*}}$
}

\section{"Correspondence:}

emscolar@yahoo.com

${ }^{2}$ Department of Mathematics \&

Informatics, University Politehnica of

Bucharest, Bucharest, 060042,

Romania

Full list of author information is

available at the end of the article

\begin{abstract}
The purpose of this paper is to introduce a new three step iteration scheme for approximation of fixed points of the nonexpansive mappings. We show that our iteration process is faster than all of the Picard, the Mann, the Agarwal et al., and the Abbas et al. iteration processes. We support our analytic proof by a numerical example in which we approximate the fixed point by a computer using Matlab program. We also prove some weak convergence and strong convergence theorems for the nonexpansive mappings.
\end{abstract}

MSC: $47 \mathrm{H} 09 ; 47 \mathrm{H} 10$

Keywords: fixed point; nonexpansive mapping; strong and weak convergence theorems

\section{Introduction}

Many nonlinear equations are naturally formulated as fixed point problems,

$$
x=T x,
$$

where $T$, the fixed point mapping, may be nonlinear. A solution $x^{*}$ of the problem (1.1) is called a fixed point of the mapping $T$. Consider a fixed point iteration, which is given by

$$
x_{n+1}=T x_{n} .
$$

The iterative method (1.2) is also called a Richardson iteration, a Picard iteration, or the method of successive substitution. The standard result for a fixed point iteration is the contraction mapping theorem. Indeed, the contraction mapping theorem holds on an arbitrary complete metric space; that is, if $E$ is a complete metric space with metric $d$ and $T: E \rightarrow E$ such that $d(T x, T y) \leq k d(x, y)$ for some $0 \leq k<1$ and all $x, y \in E$, then $T$ has a unique fixed point $x^{*}$ and the iterates (1.2) converge to the fixed point $x^{*}$. The Picard iteration has been successfully employed in approximating the fixed point of contraction mappings and its variants. This success, however, has not extended to nonexpansive mappings $T$ even when the existence of a fixed point of $T$ is known. Consider the simple example of a self mapping in $[0,1]$ defined by $T x=1-x$ for $0 \leq x \leq 1$. Then $T$ is a nonexpansive mapping with

\section{算 Springer}

@2014 Thakur et al.; licensee Springer. This is an Open Access article distributed under the terms of the Creative Commons Attribution License (http://creativecommons.org/licenses/by/2.0), which permits unrestricted use, distribution, and reproduction in any medium, provided the original work is properly cited. 
a unique fixed point at $x=\frac{1}{2}$. If one chooses as a starting value $x=a, a \neq \frac{1}{2}$, then the successive iterations of $T$ yield the sequence $\{1-a, a, 1-a, a, \ldots\}$. Thus when a fixed point of nonexpansive mappings exists, other approximation techniques are needed to approximate it.

Consider an average mapping of the form $T_{\frac{1}{2}}=\frac{1}{2} I+\frac{1}{2} T$, where $I$ is the identity operator. This average mapping is nonexpansive because $T$ is nonexpansive, and both have the same fixed point set. Krasnosel'skii [1] was first to notice the regularization effect of this average mapping. Schaefer [2] proved a convergence result for a general $T_{\lambda}=\lambda I+(1-\lambda) T$ $(0<\lambda<1)$. An approximation of fixed points of a nonexpansive mapping using Mann's algorithm [3] has extensively been studied in the literature (see, e.g., [4, 5] and references therein). Mann's algorithm generates, for an arbitrary $x_{0} \in C$, a sequence $\left\{x_{n}\right\}$ according to the following:

$$
x_{n+1}=\alpha_{n} x_{n}+\left(1-\alpha_{n}\right) T x_{n}, \quad n \geq 0,
$$

where $\left\{\alpha_{n}\right\}$ is a real control sequence in the interval $(0,1)$.

In 1974, Ishikawa [6] introduced an iteration process where $\left\{x_{n}\right\}$ is defined iteratively for each positive integer $n \geq 0$ by

$$
\left.\begin{array}{l}
x_{n+1}=\left(1-\alpha_{n}\right) x_{n}+\alpha_{n} T y_{n}, \\
y_{n}=\left(1-\beta_{n}\right) x_{n}+\beta_{n} T x_{n} .
\end{array}\right\}
$$

In 2000, Noor [7] introduced the following iterative scheme: for any fixed $x_{0} \in C$, construct $\left\{x_{n}\right\}$ by

$$
\left.\begin{array}{l}
x_{n+1}=\left(1-\alpha_{n}\right) x_{n}+\alpha_{n} T y_{n}, \\
y_{n}=\left(1-\beta_{n}\right) x_{n}+\beta_{n} T z_{n} \\
z_{n}=\left(1-\gamma_{n}\right) x_{n}+\gamma_{n} T x_{n}
\end{array}\right\}
$$

for all $n \geq 1$, where $\left\{\alpha_{n}\right\},\left\{\beta_{n}\right\}$, and $\left\{\gamma_{n}\right\}$ are sequences in $(0,1)$.

In 2007, Agarwal et al. [8] introduced the following iteration process: for an arbitrary $x_{0} \in C$ construct a sequence $\left\{x_{n}\right\}$ by

$$
\left.\begin{array}{l}
x_{n+1}=\left(1-\alpha_{n}\right) T x_{n}+\alpha_{n} T y_{n}, \\
y_{n}=\left(1-\beta_{n}\right) x_{n}+\beta_{n} T x_{n}, \quad n \in \mathbb{N},
\end{array}\right\}
$$

where $\left\{\alpha_{n}\right\}$ and $\left\{\beta_{n}\right\}$ are in $(0,1)$. They showed that this process converges at ate that is the same as that of the Picard iteration and faster than the Mann iteration for contractions.

Recently, Abbas and Nazir [9] introduced the following iteration: for an arbitrary $x_{0} \in C$ construct $\left\{x_{n}\right\}$ by

$$
\left.\begin{array}{l}
x_{n+1}=\left(1-\alpha_{n}\right) T y_{n}+\alpha_{n} T z_{n}, \\
y_{n}=\left(1-\beta_{n}\right) T x_{n}+\beta_{n} T z_{n}, \\
z_{n}=\left(1-\gamma_{n}\right) x_{n}+\gamma_{n} T x_{n},
\end{array}\right\}
$$

where $\left\{\alpha_{n}\right\},\left\{\beta_{n}\right\}$, and $\left\{\gamma_{n}\right\}$ are in $(0,1)$. They showed that this process converges faster than the Agarwal et al. [8] iteration process. 
Motivated and inspired by the above work, in this paper we introduce a new iterative scheme, where the sequence $\left\{x_{n}\right\}$ is generated from arbitrary $x_{0} \in C$ by

$$
\left.\begin{array}{l}
x_{n+1}=\left(1-\alpha_{n}\right) T x_{n}+\alpha_{n} T y_{n}, \\
y_{n}=\left(1-\beta_{n}\right) z_{n}+\beta_{n} T z_{n}, \\
z_{n}=\left(1-\gamma_{n}\right) x_{n}+\gamma_{n} T x_{n},
\end{array}\right\}
$$

where $\left\{\alpha_{n}\right\},\left\{\beta_{n}\right\}$, and $\left\{\gamma_{n}\right\}$ are real sequences in $(0,1)$.

The purpose of this paper is to prove that our process (1.8) converges faster than all of the Picard, the Mann, the Ishikawa, the Noor, the Agarwal et al., and the Abbas et al. iteration processes for contractions in the sense of Berinde [10]. We also prove weak and strong convergence theorems for nonexpansive mapping using iteration (1.8). In the last section, using a numerical example, we compare the behavior of iteration (1.8) with respect to the above mentioned iteration processes.

\section{Rate of convergence}

Berinde [10] proposed a method to compare the fastness of two sequences.

Definition 2.1 Let $\left\{a_{n}\right\}$ and $\left\{b_{n}\right\}$ be two sequences of real numbers that converge to $a$ and $b$, respectively, and assume that there exists

$$
l=\lim _{n \rightarrow \infty} \frac{\left|a_{n}-a\right|}{\left|b_{n}-b\right|} .
$$

(i) If $l=0$, then it can be said that $\left\{a_{n}\right\}$ converges faster to $a$ than $\left\{b_{n}\right\}$ to $b$.

(ii) If $0<l<\infty$, then it can be said that $\left\{a_{n}\right\}$ and $\left\{b_{n}\right\}$ have the same rate of convergence.

Suppose that, for two fixed point iteration procedures $\left\{u_{n}\right\}$ and $\left\{v_{n}\right\}$, both converging to the same fixed point $p$, the error estimates

$$
\begin{aligned}
& \left\|u_{n}-p\right\| \leq a_{n}, \quad n=0,1,2, \ldots \\
& \left\|v_{n}-p\right\| \leq b_{n}, \quad n-=0,1,2, \ldots
\end{aligned}
$$

are available, where $\left\{a_{n}\right\}$ and $\left\{b_{n}\right\}$ are sequences of positive numbers (converging to zero).

Then, in view of Definition 2.1, Berinde [10] adopted the following concept.

Definition 2.2 Let $\left\{u_{n}\right\}$ and $\left\{v_{n}\right\}$ be two fixed point iteration procedures that converge to the same fixed point $p$ and satisfy (2.2) and (2.3), respectively. If $\left\{a_{n}\right\}$ converges faster than $\left\{b_{n}\right\}$, then it can be said that $\left\{u_{n}\right\}$ converges faster than $\left\{v_{n}\right\}$ to $p$.

In recent years, Definition 2.2 has been used as a standard tool to compare the fastness of two fixed point iterations. Using this technique Sahu [11] established that the Agarwal et al. iteration (1.6) converges faster than the Mann (1.3) and the Picard (1.2) iterations and supported the claim by the following example.

Example 1 Let $X=\mathbb{R}$ and $K=[0, \infty)$. Let $T: K \rightarrow K$ be a mapping defined by $T x=(3 x+$ $18)^{\frac{1}{3}}$ for all $x \in K$. For $x_{0}=1,000$ and $\alpha_{n}=\beta_{n}=\frac{1}{2}, n=0,1,2, \ldots$, Agarwal et al. iteration is faster than both the Mann and the Picard iteration. 
Using a similar technique Abbas and Nazir [9] established that the Abbas et al. iteration (1.7) converges faster than the Agarwal et al. iteration (1.6) and hence it converges faster than the Mann (1.3) and the Picard (1.2) iterations also. An example is also given in support of the claim.

Example 2 Let $X=\mathbb{R}$ and $K=[1,50]$. Let $T: K \rightarrow K$ be a mapping defined by $T x=$ $\sqrt{x^{2}-8 x+40}$ for all $x \in K$. For $x_{0}=30$ and $\alpha_{n}=\beta_{n}=\gamma_{n}=\frac{1}{2}, n=0,1,2, \ldots$, the Abass et al. iteration (1.7) is faster than the Agarwal et al. iteration (1.6). Since Sahu [11] already has shown that the iteration (1.6) is faster than the Mann iteration (1.3), the iteration (1.7) is faster than the iterations (1.2), (1.3), and (1.6).

We now show that our process (1.8) converges faster than (1.7) in the sense of Berinde [10].

Theorem 2.3 Let $C$ be a nonempty closed convex subset of a norm space E. Let $T$ be a contraction with a contraction factor $k \in(0,1)$ and fixed point $p$. Let $\left\{u_{n}\right\}$ be defined by the iteration process (1.7) and $\left\{x_{n}\right\}$ by (1.8), where $\left\{\alpha_{n}\right\},\left\{\beta_{n}\right\}$, and $\left\{\gamma_{n}\right\}$ are in $[\varepsilon, 1-\varepsilon]$ for all $n \in \mathbb{N}$ and for some $\varepsilon$ in $(0,1)$. Then $\left\{x_{n}\right\}$ converges faster than $\left\{u_{n}\right\}$. That is, our process (1.8) converges faster than (1.7).

Proof As proved in Theorem 3 of Abbas and Nazir [9],

$$
\left\|u_{n+1}-p\right\| \leq k^{n}[1-(1-k) \alpha \beta \gamma]^{n}\left\|u_{1}-p\right\|
$$

for all $n \in \mathbb{N}$. Let

$$
a_{n}=k^{n}[1-(1-k) \alpha \beta \gamma]^{n}\left\|u_{1}-p\right\| .
$$

Now

$$
\begin{aligned}
\left\|z_{n}-p\right\| & =\left\|\left(1-\gamma_{n}\right) x_{n}+\gamma_{n} T x_{n}-p\right\| \\
& \leq\left(1-\gamma_{n}\right)\left\|x_{n}-p\right\|+k \gamma_{n}\left\|x_{n}-p\right\| \\
& =\left(1-(1-k) \gamma_{n}\right)\left\|x_{n}-p\right\|,
\end{aligned}
$$

so that

$$
\begin{aligned}
\left\|y_{n}-p\right\| & =\left\|\left(1-\beta_{n}\right) z_{n}+\beta_{n} T z_{n}-p\right\| \\
& \leq\left(1-\beta_{n}\right)\left\|z_{n}-p\right\|+k \beta_{n}\left\|z_{n}-p\right\| \\
& \leq\left(1-\beta_{n}\right)\left(1-(1-k) \gamma_{n}\right)\left\|x_{n}-p\right\|+k \beta_{n}\left(1-(1-k) \gamma_{n}\right)\left\|x_{n}-p\right\| \\
& =\left(1-(1-k) \beta_{n}\right)\left(1-(1-k) \gamma_{n}\right)\left\|x_{n}-p\right\| .
\end{aligned}
$$

Thus

$$
\begin{aligned}
\left\|x_{n+1}-p\right\| & =\left\|\left(1-\alpha_{n}\right) T x_{n}+\alpha_{n} T y_{n}-p\right\| \\
& \leq\left(1-\alpha_{n}\right) k\left\|x_{n}-p\right\|+k \alpha_{n}\left\|y_{n}-p\right\|
\end{aligned}
$$




$$
\begin{aligned}
& \leq\left(1-\alpha_{n}\right) k\left\|x_{n}-p\right\|+k \alpha_{n}\left(1-(1-k) \beta_{n}\right)\left(1-(1-k) \gamma_{n}\right)\left\|x_{n}-p\right\| \\
& =k\left[1-\alpha_{n}+\alpha_{n}\left(1-(1-k) \beta_{n}\right)\left(1-(1-k) \gamma_{n}\right)\right]\left\|x_{n}-p\right\| \\
& =k\left[1-\alpha_{n}+\left(\alpha_{n}-(1-k) \alpha_{n} \beta_{n}\right)\left(1-(1-k) \gamma_{n}\right)\right]\left\|x_{n}-p\right\| \\
& =k\left[1-\alpha_{n}+\alpha_{n}-(1-k) \alpha_{n} \gamma_{n}-(1-k) \alpha_{n} \beta_{n}+(1-k)^{2} \alpha_{n} \beta_{n} \gamma_{n}\right]\left\|x_{n}-p\right\| \\
& \leq k\left[1-(1-k) \alpha_{n} \beta_{n} \gamma_{n}-(1-k) \alpha_{n} \beta_{n} \gamma_{n}+(1-k)^{2} \alpha_{n} \beta_{n} \gamma_{n}\right]\left\|x_{n}-p\right\| \\
& =k\left(1-(1-k)(1+k) \alpha_{n} \beta_{n} \gamma_{n}\right)\left\|x_{n}-p\right\| \\
& =k\left(1-\left(1-k^{2}\right) \alpha_{n} \beta_{n} \gamma_{n}\right)\left\|x_{n}-p\right\| .
\end{aligned}
$$

Let

$$
b_{n}=k^{n}\left(1-\left(1-k^{2}\right) \alpha \beta \gamma\right)^{n}\left\|x_{1}-p\right\| .
$$

Then

$$
\begin{aligned}
\frac{b_{n}}{a_{n}} & =\frac{k^{n}\left(1-\left(1-k^{2}\right) \alpha \beta \gamma\right)^{n}\left\|x_{1}-p\right\|}{k^{n}[1-(1-k) \alpha \beta \gamma]^{n}\left\|u_{1}-p\right\|} \\
& =\frac{\left(1-\left(1-k^{2}\right) \alpha \beta \gamma\right)^{n}}{(1-(1-k) \alpha \beta \gamma)^{n}} \frac{\left\|x_{1}-p\right\|}{\left\|u_{1}-p\right\|} \\
& \rightarrow 0 \quad \text { as } n \rightarrow \infty .
\end{aligned}
$$

Consequently $\left\{x_{n}\right\}$ converges faster than $\left\{u_{n}\right\}$.

Now, we present an example which shows that the new iteration process (1.8) converges at a rate faster than the existing iteration schemes mentioned above.

Example 3 Let $E=\mathbb{R}$ and $C=[1,50]$. Let $T: C \rightarrow C$ be a mapping defined by $T(x)=$ $\sqrt{x^{2}-8 x+40}$ for all $x \in C$. Choose $\alpha_{n}=0.85, \beta_{n}=0.65, \gamma_{n}=0.45$, with the initial value $x_{1}=40$. Our corresponding iteration process, the Abbas and Nazir iteration process (1.7), the Agarwal et al. iteration process (1.6), the Noor iteration process (1.7), the Ishikawa iteration process (1.4), the Mann iteration process (1.3), and the Picard iteration processes (1.2) are, respectively, given in Table 1.

All sequences converge to $x^{*}=5$. Comparison shows that our iteration process (1.8) converges fastest among all the iterations considered in the example.

\section{Convergence theorems}

In this section, we give some convergence theorems using our iteration process (1.8); please, see Table 1 and Figure 1.

Lemma 3.1 Let $C$ be a nonempty closed convex subset of a norm space E. Let $T$ be a nonexpansive self mapping on $C,\left\{x_{n}\right\}$ defined by (1.8) and $F(T) \neq \emptyset$. Then $\lim _{n \rightarrow \infty}\left\|x_{n}-p\right\|$ exists for all $p \in F$. 
Table 1 Comparative results

\begin{tabular}{|c|c|c|c|c|c|c|c|}
\hline Step & Picard & Mann & Ishikawa & Noor & Agarwal & Abbas & New iter. \\
\hline 1 & 0000000000 & .0000000000 & 40.0000000000 & 40.0000000000 & 40.0000000000 & 40.0000000000 & 000000 \\
\hline 2 & 36.3318042492 & 36.8820336118 & 34.8751575132 & 33.9816211055 & 34.3249281505 & 34.2399531822 & 32.9458774280 \\
\hline 3 & 32.7008496221 & 33.7905308732 & 29.8335259837 & 28.0882816012 & 48550 & 017 & 2526 \\
\hline 4 & 29.1159538575 & 30.7306375124 & 24.9067432334 & 22.3811620460 & 23.3289757744 & 5148078 & \\
\hline 5 & 25.5892777970 & 27.7090706072 & 20.1467307646 & 16.9736024952 & 18.1321892967 & 17.8350979079 & 477938 \\
\hline 6 & 22.1381326176 & 24.7347891266 & 15.6449263114 & 12.0962209155 & 54600 & 4680 & \\
\hline 7 & 18.7880774656 & 21.8200359935 & 11.5741197024 & 8.2289280979 & 9.1939307941 & 413368 & 50470 \\
\hline 8 & 15.5784221001 & 18.9820007784 & 8.2638548016 & 6.0182077910 & 3717274607 & 180 & 1830 \\
\hline 9 & 21859009 & 16.2 & 982 & 165 & 591 & & \\
\hline 10 & & 13.6475866165 & 5.3185408455 & 5955 & & & \\
\hline 11 & 7.6482574613 & 11.2442765494 & 5.0768890301 & 5.0129 & 656 & 692 & 381 \\
\hline 12 & 180 & 370 & 209 & 212 & 718 & & \\
\hline 13 & & & & & & & \\
\hline 14 & 7771808572 & 225 & 150 & 769 & 858 & 253 & 244 \\
\hline 15 & 399 & & 577 & 584 & 229 & & \\
\hline 16 & & & & & & & \\
\hline 17 & 5.0006461643 & 946 & 0186 & 240 & 065 & 062 & 000 \\
\hline 18 & 5.0001292729 & 9301 & 7835 & 632 & 007 & 007 & 1000 \\
\hline 19 & & & & & & & \\
\hline 20 & 000051713 & 86052 & 493 & 182 & 000 & 500 & 000 \\
\hline 21 & 000010343 & 6174572 & 346 & 041 & 000 & 000 & 000 \\
\hline 22 & & & & & & & \\
\hline 23 & 000000414 & 2408 & 019 & 002 & 000 & 000 & 000 \\
\hline 24 & 000083 & 2374 & 004 & 000 & 000 & 500 & 000 \\
\hline 25 & & & & & 000000 & & 000 \\
\hline 26 & 5.0000000003 & 5.0000020723 & 5.0000000000 & 0000 & 0000 & 000 & 000 \\
\hline 27 & 5.0000000001 & 5.0000006631 & 5.0000000000 & 0000 & 000 & 000 & 000 \\
\hline 28 & & 02122 & & & 0000 & & \\
\hline 29 & 5.0000000000 & & 5.0000000000 & 5.0000000000 & 000000000 & 000 & 000 \\
\hline 30 & 5.0000000000 & 5.0000000217 & 0000 & 000 & 000 & 500 & 0000 \\
\hline 31 & 5.0000000000 & 5.0000000070 & 5.0000000000 & 5.0000000000 & 5.0000000000 & 5.0000000000 & 000000 \\
\hline 32 & 5.0000000000 & 5.0000000022 & 5.0000000000 & 5.0000000000 & 5.0000000000 & 5.0000000000 & 5.0000000000 \\
\hline 33 & 5.0000000000 & 5.0000000007 & 5.0000000000 & 5.0000000000 & 5.0000000000 & 5.0000000000 & 5.0000000000 \\
\hline 34 & 5.0000000000 & 5.0000000002 & 5.0000000000 & 5.0000000000 & 5.0000000000 & 5.0000000000 & 5.0000000000 \\
\hline 35 & 5.0000000000 & 5.0000000001 & 5.0000000000 & 5.0000000000 & 5.0000000000 & 5.0000000000 & 5.0000000000 \\
\hline
\end{tabular}
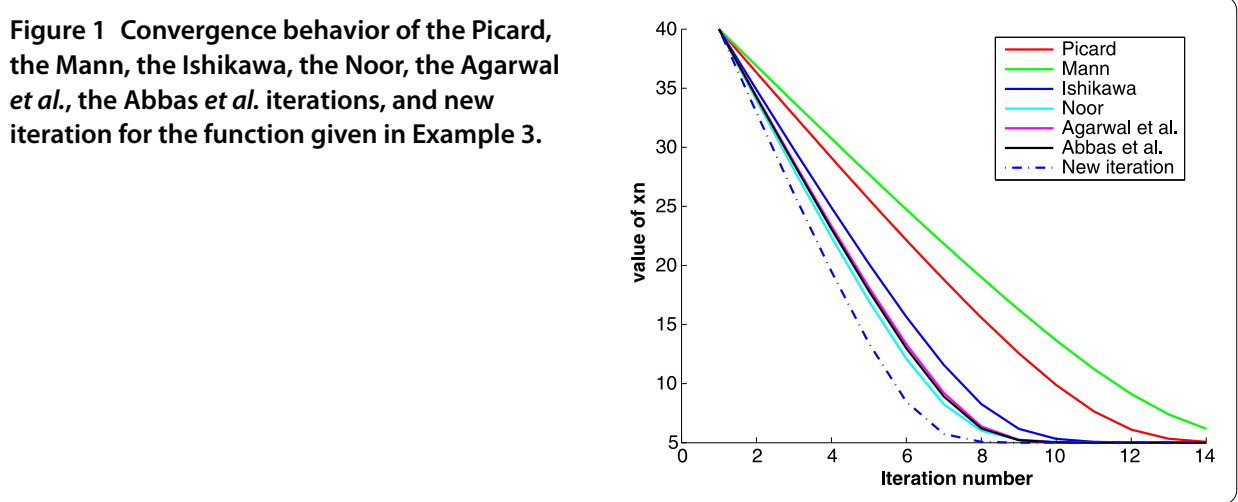

Proof Let $p \in F(T)$ for all $n \in \mathbb{N}$. From (1.8), we have

$$
\begin{aligned}
\left\|z_{n}-p\right\| & =\left\|\left(1-\gamma_{n}\right) x_{n}+\gamma_{n} T x_{n}-p\right\| \\
& \leq\left(1-\gamma_{n}\right)\left\|x_{n}-p\right\|+\gamma_{n}\left\|T x_{n}-p\right\| \\
& \leq\left(1-\gamma_{n}\right)\left\|x_{n}-p\right\|+\gamma_{n}\left\|x_{n}-p\right\| \\
& =\left\|x_{n}-p\right\|
\end{aligned}
$$


and

$$
\begin{aligned}
\left\|y_{n}-p\right\| & =\left\|\left(1-\beta_{n}\right) z_{n}+\beta_{n} T z_{n}-p\right\| \\
& \leq\left(1-\beta_{n}\right)\left\|z_{n}-p\right\|+\beta_{n}\left\|T z_{n}-p\right\| \\
& \leq\left(1-\beta_{n}\right)\left\|x_{n}-p\right\|+\beta_{n}\left\|x_{n}-p\right\| \\
& =\left\|x_{n}-p\right\|,
\end{aligned}
$$

thus from (3.1) and (3.2)

$$
\begin{aligned}
\left\|x_{n+1}-p\right\| & =\left\|\left(1-\alpha_{n}\right) T x_{n}+\alpha_{n} T y_{n}-p\right\| \\
& \leq\left(1-\alpha_{n}\right)\left\|T x_{n}-p\right\|+\alpha_{n}\left\|T y_{n}-p\right\| \\
& \leq\left(1-\alpha_{n}\right)\left\|x_{n}-p\right\|+\alpha_{n}\left\|x_{n}-p\right\| \\
& =\left\|x_{n}-p\right\| .
\end{aligned}
$$

Thus $\lim _{n \rightarrow \infty}\left\|x_{n}-p\right\|$ exists for all $p \in F(T)$.

We need following lemma to establish our next result.

Lemma 3.2 [12] Suppose that $E$ is a uniformly convex Banach space and $0<p \leq t_{n} \leq q<1$ for all $n \in \mathbb{N}$. Let $\left\{x_{n}\right\}$ and $\left\{y_{n}\right\}$ be two sequences of $E$ such that $\lim _{\sup _{n \rightarrow \infty}}\left\|x_{n}\right\| \leq r$, $\limsup _{n \rightarrow \infty}\left\|y_{n}\right\| \leq r$ and $\limsup _{n \rightarrow \infty}\left\|t_{n} x_{n}+\left(1-t_{n}\right) y_{n}\right\|=r$ hold for some $r \geq 0$. Then $\lim _{n \rightarrow \infty}\left\|x_{n}-y_{n}\right\|=0$.

We now establish a result which will be of key importance for the main result.

Lemma 3.3 Let $C$ be a nonempty closed convex subset of a uniformly convex Banach space E. Let $T$ be a nonexpansive self mapping on $C,\left\{x_{n}\right\}$ defined by (1.8), where $\left\{\alpha_{n}\right\}$, $\left\{\beta_{n}\right\}$, and $\left\{\gamma_{n}\right\}$ are in $[\varepsilon, 1-\varepsilon]$ for all $n \in \mathbb{N}$ and for some $\varepsilon$ in $(0,1)$ and $F(T) \neq \emptyset$. Then $\lim _{n \rightarrow \infty}\left\|x_{n}-T x_{n}\right\|=0$.

Proof By Lemma 3.1, $\lim _{n \rightarrow \infty}\left\|x_{n}-p\right\|$ exists. Assume that $\lim _{n \rightarrow \infty}\left\|x_{n}-p\right\|=c$.

From (3.1) and (3.2) we have

$$
\limsup _{n \rightarrow \infty}\left\|y_{n}-p\right\| \leq c
$$

and

$$
\limsup _{n \rightarrow \infty}\left\|z_{n}-p\right\| \leq c
$$

Since $T$ is a nonexpansive mapping, it follows that

$$
\left\|T x_{n}-p\right\| \leq\left\|x_{n}-p\right\|
$$


and

$$
\left\|T y_{n}-p\right\| \leq\left\|y_{n}-p\right\|
$$

Taking lim sup on both sides, we obtain

$$
\limsup _{n \rightarrow \infty}\left\|T x_{n}-p\right\| \leq c
$$

and

$$
\limsup _{n \rightarrow \infty}\left\|T y_{n}-p\right\| \leq c
$$

Since

$$
c=\lim _{n \rightarrow \infty}\left\|x_{n+1}-p\right\|=\lim _{n \rightarrow \infty}\left\|\left(1-\alpha_{n}\right)\left(T x_{n}-p\right)+\alpha_{n}\left(T y_{n}-p\right)\right\|,
$$

by using Lemma 3.2, we have

$$
\lim _{n \rightarrow \infty}\left\|T x_{n}-T y_{n}\right\|=0
$$

Now

$$
\left\|x_{n+1}-p\right\|=\left\|\left(1-\alpha_{n}\right) T x_{n}+\alpha_{n} T y_{n}-p\right\| \leq\left\|T x_{n}-p\right\|+\alpha_{n}\left\|T x_{n}-T y_{n}\right\|
$$

yields

$$
c \leq \liminf _{n \rightarrow \infty}\left\|T x_{n}-p\right\|,
$$

so that (3.5) and (3.8) give

$$
\lim _{n \rightarrow \infty}\left\|T x_{n}-p\right\|=c
$$

On the other hand, we have

$$
\left\|T x_{n}-p\right\| \leq\left\|T x_{n}-T y_{n}\right\|+\left\|T y_{n}-p\right\| \leq\left\|T x_{n}-T y_{n}\right\|+\left\|y_{n}-p\right\|,
$$

which yields

$$
c \leq \liminf _{n \rightarrow \infty}\left\|y_{n}-p\right\| .
$$

From (3.3) and (3.10) we get

$$
\lim _{n \rightarrow \infty}\left\|y_{n}-p\right\|=c .
$$

Since $T$ is a nonexpansive mapping, we have from (3.1)

$$
\limsup _{n \rightarrow \infty}\left\|T z_{n}-p\right\| \leq c .
$$


From (3.4) and (3.11), by using Lemma 3.2 we obtain

$$
\lim _{n \rightarrow \infty}\left\|z_{n}-T z_{n}\right\|=0
$$

Since

$$
\left\|y_{n}-p\right\| \leq\left\|z_{n}-p\right\|+\beta_{n}\left\|T z_{n}-z_{n}\right\|,
$$

we write

$$
c \leq \limsup _{n \rightarrow \infty}\left\|z_{n}-p\right\|
$$

then

$$
\left\|z_{n}-p\right\|=c
$$

SO

$$
\begin{aligned}
c & =\lim _{n \rightarrow \infty}\left\|z_{n}-p\right\| \\
& =\lim _{n \rightarrow \infty}\left\|\left(1-\alpha_{n}\right) x_{n}+\alpha_{n} T x_{n}-p\right\| \\
& =\lim _{n \rightarrow \infty}\left\|\left(1-\alpha_{n}\right)\left(x_{n}-p\right)+\alpha_{n}\left(T x_{n}-p\right)\right\|,
\end{aligned}
$$

and by Lemma 3.2, we have

$$
\lim _{n \rightarrow \infty}\left\|x_{n}-T x_{n}\right\|=0
$$

This completes the proof.

Lemma 3.4 [13] Let $C$ be a nonempty bounded closed convex subset of a uniformly convex Banach space and $T: C \rightarrow$ E be a nonexpansive mapping. Then there is a strictly increasing and continuous convex function $g:[0, \infty) \rightarrow[0, \infty)$ with $g(0)=0$ such that

$$
g(\|T(t x+(1-t) y)-(t T x+(1-t) T y)\|) \leq\|x-y\|-\|T x-T y\|
$$

for all $x, y \in C$ and $t \in[0,1]$.

Lemma 3.5 For any $p_{1}, p_{2} \in F(T), \lim _{n \rightarrow \infty}\left\|t x_{n}+(1-t) p_{1}-p_{2}\right\|$ exists, for all $t \in[0,1]$ under the conditions of Lemma 3.3.

Proof By Lemma 3.1, $\lim _{n \rightarrow \infty}\left\|x_{n}-p\right\|$ exists for all $p \in F(T)$ and hence $\left\{x_{n}\right\}$ is bounded. Thus there exists a real number $r>0$ such that $\left\{x_{n}\right\} \subseteq D \equiv \overline{B_{r}(0)} \cap C$, so that $D$ is a closed convex nonempty subset of $C$. Set

$$
a_{n}(t):=\left\|t x_{n}+(1-t) p_{1}-p_{2}\right\|
$$


for all $t \in[0,1]$. Then $\lim _{n \rightarrow \infty} a_{n}(0)=\left\|p_{1}-p_{2}\right\|$ and, from Lemma 3.1, $\lim _{n \rightarrow \infty} a_{n}(1)=\| x_{n}-$ $p_{2} \|$ exist.

Now it remains to show that $\lim _{n \rightarrow \infty} a_{n}(t)$ exists for $t \in(0,1)$.

For each $n \in N$, define $W_{n}: D \rightarrow D$ by

$$
\left\{\begin{array}{l}
W_{n} x=\left(1-\alpha_{n}\right) T x+\alpha_{n} T V_{n} x, \\
V_{n} x=\left(1-\beta_{n}\right) U_{n} x+\beta_{n} T U_{n} x \\
U_{n} x=\left(1-\gamma_{n}\right) x+\gamma_{n} T x
\end{array}\right.
$$

for all $x \in D$.

We see that

$$
\left\|U_{n} x-U_{n} y\right\| \leq\|x-y\|, \quad \forall x, y \in D,
$$

and

$$
\left\|V_{n} x-V_{n} y\right\| \leq\|x-y\|, \quad \forall x, y \in D,
$$

hence,

$$
\left\|W_{n} x-W_{n} y\right\| \leq\|x-y\|, \quad \forall x, y \in D
$$

Set

$$
R_{n, m}=W_{n+m-1} W_{n+m-2} \cdots W_{n}
$$

and

$$
b_{n . m}=\left\|R_{n, m}\left(t x_{n}+(1-t) p_{1}\right)-\left(t R_{n, m} x_{n}+(1-t) p_{1}\right)\right\|,
$$

for all $n, m \in N$. Then $R_{n, m} x_{n}=x_{n+m}$ and $R_{n, m} p=p \forall p \in F(T)$. Also,

$$
\left\|R_{n, m} x-R_{n . m} y\right\| \leq\|x-y\|, \quad \forall x, y \in D .
$$

By Lemma 3.4, there exists a strictly increasing continuous function $g:[0, \infty) \rightarrow[0, \infty)$ with $g(0)=0$ such that

$$
\begin{aligned}
g\left(b_{n, m}\right) & \leq\left\|x_{n}-p_{1}\right\|-\left\|R_{n, m} x_{n}-R_{n, m} p_{1}\right\| \\
& =\left\|x_{n}-p_{1}\right\|-\left\|x_{n+m}-p_{1}\right\| .
\end{aligned}
$$

Since $\lim _{n \rightarrow \infty}\left\|x_{n}-p\right\|$ exists for all $p \in F(T)$, we get $\lim _{n, m \rightarrow \infty} g\left(b_{n, m}\right)=0$ and by the property of $g$, we get $\lim _{n, m \rightarrow \infty} b_{n, m}=0$.

Now,

$$
\begin{aligned}
a_{n+m}(t) & =\left\|t x_{n+m}+(1-t) p_{1}-p_{2}\right\| \\
& =\left\|t R_{n, m} x_{n}+(1-t) p_{1}-p_{2}\right\|
\end{aligned}
$$




$$
\begin{aligned}
& \leq b_{n, m}+\left\|R_{n, m}\left(t x_{n}+(1-t) p_{1}\right)-p_{2}\right\| \\
& =b_{n, m}+\left\|R_{n, m}\left(t x_{n}+(1-t) p_{1}\right)-R_{n, m} p_{2}\right\| \\
& \leq b_{n, m}+\left\|\left(t x_{n}+(1-t) p_{1}\right)-p_{2}\right\| \\
& =b_{n, m}+a_{n}(t) .
\end{aligned}
$$

Consequently

$$
\begin{aligned}
\limsup _{m \rightarrow \infty} a_{m}(t) & =\limsup _{m \rightarrow \infty} a_{n+m}(t) \\
& \leq \limsup _{m \rightarrow \infty}\left(b_{n, m}\right)+a_{n}(t)
\end{aligned}
$$

Since $\lim _{n, m \rightarrow \infty} b_{n, m}=0$, we get

$$
\limsup _{n \rightarrow \infty} a_{n}(t) \leq \liminf _{n \rightarrow \infty} a_{n}(t)
$$

This implies that $\lim _{n \rightarrow \infty} a_{n}(t)$ exists for all $t \in(0,1)$, i.e., $\lim _{n \rightarrow \infty}\left\|t x_{n}+(1-t) p_{1}-p_{2}\right\|$ exists for all $t \in[0,1]$.

Let $E$ be a Banach space and $S_{E}=\{x \in E:\|x\|=1\}$ unit sphere on $E$. The Banach space $E$ is said to be smooth if

$$
\lim _{t \rightarrow 0} \frac{\|x+t y\|-\|x\|}{t}
$$

exists for each $x$ and $y$ in $S_{E}$. In this case, the norm of $E$ is called Gâteaux differentiable.

The space $E$ is called Fréchet differentiable normed (see, e.g., [14]); for each $x$ in $E$, the above limit exists and is attained uniformly for $y$ in $E$, and in this case it is also well known that

$$
\langle h, J(x)\rangle+\frac{1}{2}\|x\|^{2} \leq \frac{1}{2}\|x+h\|^{2} \leq\langle h, J(x)\rangle+\frac{1}{2}\|x\|^{2}+b(\|h\|)
$$

for all $x, h \in E$, where $J$ is the Fréchet derivative of the function $\frac{1}{2}\|\cdot\|^{2}$ at $x \in E,\langle\cdot, \cdot\rangle$ is the dual pairing between $E$ and $E^{*}$, and $b$ is an increasing function defined on $[0, \infty)$ such that $\lim _{t \rightarrow 0} \frac{b(t)}{t}=0$.

Lemma 3.6 Assume that the conditions of Lemma 3.3 are satisfied. Then, for any $p_{1}, p_{2} \in$ $F(T), \lim _{n \rightarrow \infty}\left\langle x_{n}, J\left(p_{1}-p_{2}\right)\right\rangle$ exists; in particular, $\left\langle p-q, J\left(p_{1}-p_{2}\right)\right\rangle=0$ for all $p, q \in \omega_{w}\left(x_{n}\right)$, the set of all weak limits of $\left\{x_{n}\right\}$.

The proof of Lemma 3.6 is similar to the proof of Lemma 2.3 of Khan and Kim [15].

A Banach space $E$ is said to satisfy the Opial condition [16] if for each sequence $\left\{x_{n}\right\}$ in $E$, $x_{n} \rightarrow x$ implies that

$$
\limsup _{n \rightarrow \infty}\left\|x_{n}-x\right\|<\limsup _{n \rightarrow \infty}\left\|x_{n}-y\right\|
$$

for all $y \in E$ with $y \neq x$. 
A Banach space $E$ is said to have the Kadec-Klee property if for every sequence $\left\{x_{n}\right\}$ in $E$, $x_{n} \rightarrow x$ and $\left\|x_{n}\right\| \rightarrow\|x\|$ together imply $x_{n} \rightarrow x$ as $n \rightarrow \infty$.

We need the following to prove our next result.

Definition 3.7 A mapping $T: C \rightarrow E$ is demiclosed at $y \in E$ if for each sequence $\left\{x_{n}\right\}$ in $C$ and each $x \in E, x_{n} \rightarrow x$, and $T x_{n} \rightarrow y$ imply that $x \in C$ and $T x=y$.

Lemma 3.8 [17] Let $C$ be a nonempty closed convex subset of a uniformly convex Banach space $E$, and $T$ a nonexpansive mapping on $C$. Then $I-T$ is demiclosed at zero.

Lemma 3.9 [8] Let $E$ be a reflexive Banach space satisfying the Opial condition, $C$ a nonempty convex subset of $E$, and $T: C \rightarrow E$ an operator such that $I-T$ demiclosed at zero and $F(T) \neq \emptyset$. Let $\left\{x_{n}\right\}$ be a sequence in $C$ such that $\lim _{n \rightarrow \infty}\left\|x_{n}-T x_{n}\right\|=0$ and $\lim _{n \rightarrow \infty}\left\|x_{n}-p\right\|$ exists for all $p \in F(T)$. Then $\left\{x_{n}\right\}$ converges weakly to a fixed point of $T$.

Lemma 3.10 [18] Let $E$ be a real reflexive Banach space such that its dual $E^{*}$ has the Kadec-Klee property. Let $\left\{x_{n}\right\}$ be a bounded sequence in $E$ and $x^{*}, y^{*} \in \omega_{w}\left(x_{n}\right)$, here $\omega_{w}\left(x_{n}\right)$ denotes the $w$-limit set of $\left\{x_{n}\right\}$. Suppose $\lim _{n \rightarrow \infty}\left\|t x_{n}+(1-t) x^{*}-y^{*}\right\|$ exists for all $t \in[0,1]$. Then $x^{*}=y^{*}$.

We now establish a weak convergence result.

Theorem 3.11 Let E be a uniformly convex Banach space and let $C, T$, and $\left\{x_{n}\right\}$ be as in Lemma 3.3 and $F(T) \neq \emptyset$. Assume that any of the following conditions hold:

(a) E satisfies the Opial condition,

(b) E has a Fréchet differentiable norm,

(c) the dual $E^{*}$ of $E$ satisfies the Kadec-Klee property.

Then $\left\{x_{n}\right\}$ converges weakly to a point of $F(T)$.

Proof Let $p \in F(T)$, by Lemma 3.1, $\lim _{n \rightarrow \infty}\left\|x_{n}-p\right\|$ exists.

We prove that $\left\{x_{n}\right\}$ has a unique weak subsequential limit in $F(T)$.

Let $u$ and $v$ be weak limits of the subsequences $\left\{x_{n_{i}}\right\}$ and $\left\{x_{n_{j}}\right\}$ of $\left\{x_{n}\right\}$, respectively. By Lemma 3.3, $\lim _{n \rightarrow \infty}\left\|x_{n}-T x_{n}\right\|=0$, and also $I-T$ is demiclosed with respect to zero, hence by Lemma 3.8, we obtain $T u=u$. In a similar manner, we have $v \in F(T)$.

Next, we prove the uniqueness.

First assume that (a) holds. If $u \neq v$, then, by the Opial condition,

$$
\begin{aligned}
\lim _{n \rightarrow \infty}\left\|x_{n}-u\right\| & =\lim _{i \rightarrow \infty}\left\|x_{n_{i}}-u\right\|<\lim _{i \rightarrow \infty}\left\|x_{n_{i}}-v\right\|=\lim _{n \rightarrow \infty}\left\|x_{n}-v\right\| \\
& =\lim _{j \rightarrow \infty}\left\|x_{n_{j}}-v\right\|<\lim _{j \rightarrow \infty}\left\|x_{n_{j}}-u\right\|=\lim _{n \rightarrow \infty}\left\|x_{n}-u\right\| .
\end{aligned}
$$

This is a contradiction, so $u=v$.

Next, assume (b) holds.

By Lemma 3.6, $\left\langle p-q\right.$,J( $\left.\left.p_{1}-p_{2}\right)\right\rangle=0$, for all $p, q \in \omega_{w}\left(x_{n}\right)$. Therefore, $\|u-v\|^{2}=\langle u-$ $v, J(u-v)\rangle=0$ implies $u=v$.

Finally, assume that (c) is true. 
Since $\lim _{n \rightarrow \infty}\left\|t x_{n}+(1-t) u-v\right\|$ exists for all $t \in[0,1]$ by Lemma 3.5, $u=v$ by Lemma 3.10, and $\left\{x_{n}\right\}$ converges weakly to a fixed point of $F(T)$ and this completes the proof.

A mapping $T: C \rightarrow C$ is said to be semicompact if any sequence $\left\{x_{n}\right\}$ in $C$, such that $\lim _{n \rightarrow \infty}\left\|x_{n}-T x_{n}\right\|=0$, has a subsequence converging strongly to some $p \in C$.

Next we establish the following strong convergence results.

Theorem 3.12 Let E be a uniformly convex Banach space and let $C, T$, and $\left\{x_{n}\right\}$ be as in Lemma 3.3. If $T$ is semicompact and $F(T) \neq \emptyset$, then $\left\{x_{n}\right\}$ converges strongly to a fixed point of $T$.

Proof By Lemma 3.3, we have $\lim _{n \rightarrow \infty}\left\|x_{n}-T x_{n}\right\|=0$; since $T$ is semicompact, $\left\{x_{n}\right\}$ has a subsequence converging to some $p \in C$ as $C$ is closed. Continuity of $T$ gives $\lim _{j \rightarrow \infty} \| T x_{n_{j}}-$ $T p \| \rightarrow 0$. Then by Lemma 3.3,

$$
\|T p-p\|=0
$$

This yields $p \in F(T)$. By Lemma 3.1, $\lim _{n \rightarrow \infty}\left\|x_{n}-p\right\|$ exists for all $p \in F(T)$, and therefore $\left\{x_{n}\right\}$ must itself converge to $p \in F(T)$ and this completes the proof.

Theorem 3.13 Let E be a uniformly convex Banach space and let $C, T, F(T)$, and $\left\{x_{n}\right\}$ be as in Lemma 3.3. Then $\left\{x_{n}\right\}$ converges to a point of $F(T)$ if and only if $\liminf _{n \rightarrow \infty} d\left(x_{n}, F(T)\right)=$ 0 , where $d(x, F(T))=\inf \{\|x-p\|: p \in F(T)\}$.

Proof Necessity is obvious. Suppose that $\liminf _{n \rightarrow \infty} d\left(x_{n}, F(T)\right)=0$. As proved in Lemma 3.3, $\lim _{n \rightarrow \infty}\left\|x_{n}-w\right\|$ exists for all $w \in F(T)$, therefore $\lim _{n \rightarrow \infty} d\left(x_{n}, F(T)\right)$ exists. But by hypothesis, $\liminf _{n \rightarrow \infty} d\left(x_{n}, F(T)\right)=0$, therefore $\lim _{n \rightarrow \infty} d\left(x_{n}, F(T)\right)=0$.

We will show that $\left\{x_{n}\right\}$ is a Cauchy sequence in $C$. Since $\lim _{n \rightarrow \infty} d\left(x_{n}, F(T)\right)=0$, for given $\varepsilon>0$, there exists $n_{0}$ in $\mathbb{N}$ such that, for all $n \geq n_{0}$,

$$
d\left(x_{n}, F(T)\right)<\frac{\varepsilon}{2} .
$$

Particularly, $\inf \left\{\left\|x_{n_{0}}-p\right\|: p \in F(T)\right\}<\frac{\varepsilon}{2}$. Hence, there exists $p^{*} \in F(T)$ such that $\| x_{n_{0}}-$ $p^{*} \|<\frac{\varepsilon}{2}$. Now, for $m, n \geq n_{0}$,

$$
\left\|x_{n+m}-x_{n}\right\| \leq\left\|x_{n+m}-p^{*}\right\|+\left\|x_{n}-p^{*}\right\| \leq 2\left\|x_{n_{0}}-p^{*}\right\|<\varepsilon .
$$

Hence $\left\{x_{n}\right\}$ is a Cauchy sequence in $C$. Since $C$ is a closed subset of a complete space, $\lim _{n \rightarrow \infty} x_{n}=p \in C$. Since $F(T)$ is closed, $\lim _{n \rightarrow \infty} d\left(x_{n}, F(T)\right)=0$ gives $d(p, F(T))=0$, i.e., $p \in F(T)$.

Definition 3.14 A mapping $T: C \rightarrow C$, where $C$ is a subset of a normed space $E$, is said to satisfy Condition $(I)[19]$ if there exists a nondecreasing function $f:[0, \infty) \rightarrow[0, \infty)$ with $f(0)=0, f(r)>0$ for all $r \in(0,1)$ such that $\|x-T x\| \geq f(d(x, F(T)))$ for all $x \in C$ where $d(x, F(T))=\inf \{\|x-p\|: p \in F(T)\}$. 
Applying Theorem 3.13, we obtain strong convergence of the process (1.8) under Condition $(I)$ as follows.

Theorem 3.15 Let e be a uniformly convex Banach space and let $C, T$, and $\left\{x_{n}\right\}$ be as in Lemma 3.3. Let $T$ satisfy Condition (I), then $\left\{x_{n}\right\}$ converges strongly to a fixed point of $T$.

Proof We proved in Lemma 3.3 that

$$
\lim _{n \rightarrow \infty}\left\|x_{n}-T x_{n}\right\|=0 .
$$

From Condition $(I)$ and (3.17), we get

$$
\lim _{n \rightarrow \infty} f\left(d\left(x_{n}, F(T)\right)\right) \leq \lim _{n \rightarrow \infty}\left\|x_{n}-T x_{n}\right\|=0,
$$

i.e., $\lim _{n \rightarrow \infty} f\left(d\left(x_{n}, F(T)\right)\right)=0$. Since $f:[0, \infty) \rightarrow[0, \infty)$ is a nondecreasing function satisfying $f(0)=0, f(r)>0$ for all $r \in(0, \infty)$, we have

$$
\lim _{n \rightarrow \infty} d\left(x_{n}, F(T)\right)=0 .
$$

Now all the conditions of Theorem 3.13 are satisfied, therefore, by its conclusion, $\left\{x_{n}\right\}$ converges strongly to a point of $F(T)$.

\section{Competing interests}

The authors declare that they have no competing interests.

\section{Authors' contributions}

All authors read and approved the final manuscript.

\section{Author details}

'School of Studies in Mathematics, Pt. Ravishankar Shukla University, Raipur, 492010, India. ${ }^{2}$ Department of Mathematics \& Informatics, University Politehnica of Bucharest, Bucharest, 060042, Romania.

\section{Acknowledgements}

The second author would like to thank the Rajiv Gandhi National Fellowship of India for the grant (F1-17.1/2011-12/RGNF-ST-CHH-6632).

Received: 27 May 2014 Accepted: 19 August 2014 Published: 02 Sep 2014

\section{References}

1. Krasnosel'skii, MA: Two remarks on the method of successive approximations. Usp. Mat. Nauk 10, 123-127 (1955)

2. Schaefer, H: Über die methode sukzessiver approximationen. Jahresber. Dtsch. Math.-Ver. 59(1), 131-140 (1957)

3. Mann, WR: Mean value methods in iteration. Proc. Am. Math. Soc. 4, 506-510 (1953)

4. Byrne, C: A unified treatment of some iterative algorithms in signal processing and image reconstruction. Inverse Probl. 20(1), 103-120 (2004)

5. Kim, TH, Xu, HK: Strong convergence of modified Mann iterations. Nonlinear Anal. 61(1-2), 51-60 (2005)

6. Ishikawa, S: Fixed points by a new iteration method. Proc. Am. Math. Soc. 44, 147-150 (1974)

7. Noor, MA: New approximation schemes for general variational inequalities. J. Math. Anal. Appl. 251(1), $217-229$ (2000)

8. Agarwal, RP, O'Regan, D, Sahu, DR: Iterative construction of fixed points of nearly asymptotically nonexpansive mappings. J. Nonlinear Convex Anal. 8(1), 61-79 (2007)

9. Abbas, M, Nazir, T: A new faster iteration process applied to constrained minimization and feasibility problems. Mat. Vesn. 66(2), 223-234 (2014)

10. Berinde, $\mathrm{V}$ : Picard iteration converges faster than Mann iteration for a class of quasicontractive operators. Fixed Point Theory Appl. 2, 97-105 (2004)

11. Sahu, DR: Applications of the S-iteration process to constrained minimization problems and split feasibility problem. Fixed Point Theory 12(1), 187-204 (2011)

12. Schu, J: Weak and strong convergence to fixed points of asymptotically nonexpansive mappings. Bull. Aust. Math. Soc. 43(1), 153-159 (1991)

13. Bruck, RE: A simple proof of the mean ergodic theorem for nonlinear contractions in Banach spaces. Isr. J. Math 32(2-3), 107-116 (1979) 
14. Takahashi, W, Kim, GE: Approximating fixed points of nonexpansive mappings in Banach spaces. Math. Jpn. 48(1), 1-9 (1998)

15. Khan, SH, Kim, JK: Common fixed points of two nonexpansive mappings by a modified faster iteration scheme. Bull. Korean Math. Soc. 47(5), 973-985 (2010)

16. Opial, Z: Weak convergence of the sequence of successive approximations for nonexpansive mappings. Bull. Am. Math. Soc. 73, 591-597 (1967)

17. Goebel, K, Kirk, WA: Topics in Metric Fixed Point Theory. Cambridge Studies in Advanced Mathematics, vol. 28. Cambridge University Press, Cambridge (1990)

18. Kaczor, W: Weak convergence of almost orbits of asymptotically nonexpansive semigroups. J. Math. Anal. Appl. 272(2), 565-574 (2002)

19. Senter, HF, Dotson, WG: Approximating fixed points of nonexpansive mappings. Proc. Am. Math. Soc. 44, 375-380 (1974)

10.1186/1029-242X-2014-328

Cite this article as: Thakur et al.: New iteration scheme for numerical reckoning fixed points of nonexpansive mappings. Journal of Inequalities and Applications 2014, 2014:328

\section{Submit your manuscript to a SpringerOpen ${ }^{\circ}$ journal and benefit from:}

- Convenient online submission

- Rigorous peer review

- Immediate publication on acceptance

- Open access: articles freely available online

- High visibility within the field

- Retaining the copyright to your article 